БОЛЬШАКОВА Юлия Михайловна - кандидат политических наук, старший научный сотрудник Института политической психологии и прикладных политических исследований Ленинградского государственного университета им. А.С. Пушкина (196605, Россия, г. Санкт-Петербург, Пушкин, Петербургское ш., 10; academy.prof.com@gmail.com)

\title{
ИННОВАЦИИ В ПРОИЗВОДСТВЕ ПУБЛИЧНЫХ УСЛУГ: ОСНОВНЫЕ НАПРАВЛЕНИЯ И СМЕЖНЫЕ ОБЛАСТИ (обзор литературы)
}

\begin{abstract}
Аннотация. Работа посвящена исследованию инноваций в сфере публичных услуг. Автор предлагает обзор литературы по инновациям в государственном секторе, выявляет проблематику, направления современных исследований и смежные области и делает вывод о растущем интересе к инновациям как средству повышения эффективности и качества публичных услуг. В статье показано, что изменение в подходах к инновациям в государственном секторе активизировало развитие соответствующих направлений практической деятельности, а также научный интерес к таким смежным темам, как вовлечение заинтересованных сторон, лидерство, сетевое управление, роль граждан в инновационном процессе, ценностное измерение инноваций и т.д. При констатации несомненного развития управления в направлении инновационности в широком ее понимании автор делает вывод, что сфера публичного управления является наиболее инерционной в отношении инновационного развития.
\end{abstract}

Ключевые слова: инновации, социальные инновации, публичная услуга, публичное управление, совместное производство публичных услуг, краудсорсинг, ценности, лидерство, политические сети

$\prod$ анная работа посвящена особому классу инноваций - инновациям в управлении. На сегодняшний день в литературе по инновациям основное внимание уделяется частному, а не государственному сектору и инновациям, которые повышают эффективность организации за счет инноваций в продуктах и процессах, а не инновациям в государственном секторе, которые направлены на повышение социальных показателей за счет реорганизации межсекторальных систем принятия решений, финансирования и производства. С другой стороны, литература по вопросам управления сосредоточена на социальной координации и не опирается на литературу по инновациям [Moore, Hartley 2008: 17].

Как подчеркивают Э. Вигода-Гадот, Н. Швабски и др., за исключением небольшого числа исследований, большинство работ, посвященных инновациям в государственном секторе, являются либо теоретическими, либо ограниченными по эмпирическому охвату [Vigoda-Gadot et al. 2008]. И напротив, значительные успехи достигнуты в исследованиях инноваций в частном секTope.

Вместе с тем в последние несколько десятилетий наблюдается растущий интерес к инновациям в государственном секторе как средству повышения эффективности и качества государственных услуг. В настоящее время инновации в государственном секторе рассматриваются как открытый процесс сотрудничества между заинтересованными сторонами через различные организации. Этот поворот к открытым и совместным подходам актуализирует проблему мотивации заинтересованных сторон к присоединению к инновационному процессу.

Инновации представляют собой радикальный разрыв с прошлым [Brown, Osborne 2012]. Этот радикальный разрыв - главное отличие инноваций от улучшений. Ученые подчеркивают необходимость так называемой среды 
инноваций [Bekkers, Edelenbos, Steijn 2011]. Организации должны быть готовыми делиться жизненно важными ресурсами (такими, например, как идеи, знания и т.д.) через границы организации. Инновации в этой среде рассматриваются как процесс сотрудничества и сотворчества между заинтересованными сторонами в целях решения социальных проблем [Voorberg, Bekkers, Tummers 2015: 1340].

Таким образом, речь идет о так называемых открытых инновациях, в отличие от применяемых ранее довольно односторонних и закрытых подходов [Meijer, Bolivar 2016: 402]. Открытые инновации основаны на краудсорсинговой деятельности. Краудсорсинг представляет собой эффективный подход к решению сложных проблем, когда внутренние индивидуализированные подходы не работают.

Внедрение методологий открытых инноваций в государственном секторе может принести множество положительных результатов, среди которых повышение осведомленности о социальных проблемах, более эффективные методы, основанные на широком гражданском опыте, повышение доверия между правительством и гражданами и т.д. Однако подходы к открытым инновациям в частном секторе не могут быть просто перенесены в государственный сектор [Louis et al. 2013].

Изменение в сторону более открытого и совместного подхода к инновациям в государственном секторе активизировало развитие соответствующих направлений практической деятельности, а также научный интерес к таким смежным темам, как вовлечение заинтересованных сторон [Hartley 2005: 29], сетевое управление и доверие в этой сети [Klijn, Koppenjan 2015], роль лидера, способного объединить людей, ресурсы и идеи. Отметим, что роль самих граждан также меняется, в этой связи подчеркивается их активная и значимая роль в решении социальных проблем.

В этой связи С. Поллитт и П. Хупе подчеркивают, что социальные инновации и совместное творчество - это «волшебные концепции» [Pollitt, Hupe 2011: 651], которые в последние годы были приняты в качестве новой стратегии реформ государственного сектора, учитывая сложные социальные проблемы и бюджетные ограничения, с которыми столкнулись правительства. При этом социальные инновации определяются как создание долгосрочных результатов, направленных на удовлетворение общественных потребностей путем фундаментального изменения отношений, позиций и правил между заинтересованными сторонами посредством открытого процесса участия, обмена и сотрудничества с соответствующими заинтересованными сторонами, включая конечных пользователей, тем самым пересекая организационные границы и юрисдикции [Voorberg et al. 2014].

Важно отметить, что инновационное развитие государственного сектора в значительной степени определяется степенью готовности правительства и граждан к инновационному развитию. Здесь, как подчеркивают В. Беккерс и Л. Туммерс, возможны 4 различных сценария (4 комбинации) [Bekkers, Tummers 2018: 212].

В основе этих сценариев лежат следующие измерения: высокая/низкая степень готовности со стороны правительства и высокая/низкая степень готовности со стороны граждан. В этом контексте исследователи задаются вопросом, насколько различные традиции управления влияют на основные используемые конфигурации и как их можно изменить с помощью политических мер, руководства и т.д. [Bekkers, Tummers 2018].

Довольно много известно об инновационном потенциале отдельной организации, но инновационный потенциал «координационной» организации дол- 
жен быть связан с инновационным потенциалом сети, в которой работает эта организация. Вопрос заключается в том, как понять взаимосвязь между инновационными качествами координационной организации и сети. Следовательно, исследования инноваций могут быть связаны с массивами знаний по сетевому управлению [Bekkers, Tummers 2018].

Другой вопрос - взаимосвязь между лидерством и внедрением инноваций, в частности, как различные типы лидерства, осуществляемые на разных уровнях, влияют на инновационный потенциал политических сетей. Такие концепции, как руководство сетевым управлением и инновационное лидерство, также должны быть осмыслены при концептуализации инноваций в государственном секторе.

М. Хансен проанализировал взаимосвязь между лидерством и внедрением инноваций, связанных с $N P M$, среди 262 датских государственных менеджеров [Hansen 2011: 288]. В рамках исследования была разработана модель для понимания отношений между лидерством, внедрением системы EHR (электронная медицинская карта) в отдельных клинических отделениях, восприятием персонала и качеством медицинской помощи. Модель использовалась для определения гипотез, которые были проверены в рамках конкретного проекта.

Результаты внедрения системы $E H R$ в каждом из клинических отделений различались в зависимости от направленности и значимости, которую руководство придает реализации, а также объема выделяемых ресурсов. В ходе исследования была подтверждена гипотеза о наличии положительной связи между более высокими уровнями директивного руководства сотрудниками в процессе внедрения и предполагаемой эффективностью инноваций в области ИКТ после внедрения.

В то же время в исследовании подчеркивается, что на этот процесс оказывают влияние и другие факторы, помимо стилей управления руководителей клинических отделений (в частности, структурные факторы на уровне департаментов, такие как ресурсы и персонал).

Фогель и Масал утверждают, что «в текущих исследованиях публичного лидерства акцент по-прежнему делается на аспекте “лидерства", а не на “публичности” и что «в исследованиях по государственному руководству необходимо уделять больше внимания самой публичности» [Vogel, Masal 2014: 1179]. До сих пор почти не проводились исследования, посвященные построению и проверке шкал измерений для конкретных аспектов государственного руководства. С одной стороны, в государственном секторе проводятся различные исследования лидерства с использованием общих концепций лидерства. Однако они не отражают в полной мере конкретные публичные аспекты лидерства в публичных организациях. В связи с этим, как отмечает Х. Рейни, «хотя практически каждый разделяет установку, что все руководители и менеджеры сталкиваются с очень похожими задачами и проблемами, все больше данных свидетельствует, что публичные менеджеры работают в условиях, которые требуют довольно специфических навыков и знаний» [Rainey 2014: 364].

Как уже указывалось, инновации в государственном секторе становятся все более совместными, в этой связи актуализируется проблематика, связанная с ценностями различных заинтересованных сторон [Moore, Hartley 2008: 4]. Компромиссы между этими ценностями также подразумевают, что важно рассматривать инновации в государственном секторе не только с точки зрения многих заинтересованных сторон, но и с точки зрения многих ценностей.

Мур и Харли в этой связи подчеркивают, что инновации в публичном управлении нуждаются в более глубоком теоретическом осмыслении и должны оце- 
ниваться с точки зрения степени, в которой они способствуют справедливости и развитию общества, а также их эффективности и действенности в достижении коллективно установленных целей [Moore, Hartley 2008: 18].

Правительства и бюрократия во всем мире часто подвергаются критике за жесткий бюрократический характер, неэффективность, отсутствие гибкости и негативное отношение к изменениям и инновациям, которые ограничивают социальный прогресс и экономический рост современных государств.

Организации государственного сектора часто неэффективны и сдерживают усилия, которые могут способствовать инновациям. Поощрение инноваций в государственном секторе требует различных видов деятельности, которые преодолевают классические бюрократические модели [Vigoda-Gadot et al. 2005: 59].

Голембевски и Вигода подчеркивают, что инновации и бюрократия составляют «странную пару» из-за многочисленных различий в основных принципах. Например, бюрократия полагается на старые организационные модели (традиции, вертикальные каналы связи, порядок и контроль), а не на инновационные (креативность, целеустремленность, автономия и ответственность). Следовательно, успешные инновации обречены на провал, если они основаны на классических бюрократических моделях [Golembiewski, Vigoda 2000: 271].

Отметим также, что чем более сложной является инновация, тем больше препятствий приходится преодолевать. Сложные инновации характеризуются нелинейными процессами и циклами обратной связи, восприятием неопределенности и страхом перед потенциальной неудачей. В то же время сложные инновации представляют большую ценность. Сложность (многомерность) инноваций положительно коррелирует с разнообразием получаемых преимуществ [Torugsa, Arundel 2016: 398].

История развития управления вообще и публичного управления в частности показывает, что при констатации несомненного развития управления в направлении инновационности в широком ее понимании и, более того, все возрастающей динамики, тем не менее, мы должны отметить имеющее место ранжирование степени динамики этой инновационности по признаку масштаба объекта управления. Именно по этой причине сфера публичного управления представляется наиболее инерционной в отношении инновационного развития.

\section{Список литературы}

Bekkers V., Edelenbos J., Steijn A. 2011. Innovation in the Public Sector. London: Palgrave Macmillan.

Bekkers V., Tummers L. 2018. Innovation in the Public Sector: Towards an Open and Collaborative Approach. - International Review of Administrative Sciences. Vol. 84. Is. 2. P. 209-213.

Brown K., Osborne S. 2012. Managing Change and Innovation in Public Service Organizations. London: Routledge.

Golembiewski R., Vigoda E. 2000. Organizational Innovation and the Science/ Craft of Management. - Current Topics in Management. Vol. 5. P. 263-280.

Hansen M. 2011. Antecedents of Organizational Innovation: The Diffusion of New Public Management into Danish Local Government. - Public Administration. Vol. 89. Is. 2. P. 285-306.

Hartley J. 2005. Innovation in Governance and Public Services: Past and Present. Public Money and Management. Vol. 25. Is. 1. P. 27-34.

Klijn E., Koppenjan J. 2015. Governance Networks in the Public Sector. London: Routledge.

Louis C., Mergel I., Bretschneider S.I., Smith J. 2013. Crowdsourcing Policy 
Innovations Using Challenge.gov. - Public Management Research Conference. Madison, WI. June 20-22.

Meijer A., Bolıvar M. 2016. Governing the Smart City: A Review of the Literature on Smart Urban Governance. - International Review of Administrative Sciences. Vol. 82. Is. 2. P. 392-408.

Moore M., Hartley J. 2008. Innovations in Governance. - Public Management Review. Vol. 10. Is. 1. P. 3-20.

Pollitt C., Hupe P. 2011. Talking about Government: The Role of Magic Concepts. Public Management Review. Vol. 13. Is. 5. P. 641-658.

Rainey H. 2014. Understanding and Managing Public Organizations. $5^{\text {th }}$ ed. N.Y.: John Wiley \& Sons.

Torugsa N., Arundel A. 2016. Complexity of Innovation in the Public Sector: A Workgroup-Level Analysis of Related Factors and Outcomes. - Public Management Review. Vol. 18. Is. 3. P. 392-416.

Vigoda-Gadot E., Shoham A., Schwabsky N., Ruvio A. 2005. Public Sector Innovation for Europe: A Multinational Eight-Country Exploration of Citizens' Perspectives. - Public Administration. Vol. 86. No. 2. P. 307-329.

Vigoda-Gadot E., Shoham A., Schwabsky N., Ruvio A. 2008. Public Sector Innovation for the Managerial and the Post-Managerial Era: Promises and Realities in A Globalizing Public Administration. - International Public Management Journal. Vol. 8. Is. 1. P. 57-81.

Vogel R., Masal D. 2014. Public Leadership: A review of the literature and framework for future research. - Public Management Review. Vol. 17. № 8. P. 1165-1189.

Voorberg W., Bekkers V.J.J.M., Tummers L.G. 2014. Co-creation in Social Innovation: A Comparative Case-study on the Influential Factors and Outcomes of Co-creation. Ottowa: IRSPM. URL: https://core.ac.uk/download/pdf/20116379.pdf (accessed 28.11.2021).

Voorberg W., Bekkers V., Tummers L. 2015. A Systematic Review of Co-creation and Co-production: Embarking on the Social Innovation Journey. - Public Management Review. Vol. 17. Is. 9. P. 1333-1357.

BOLSHAKOVA Yulia Mikhailovna, Cand.Sci. (Pol.Sci.), Senior Researcher at the Institute of Political Psychology and Applied Political Studies, Pushkin Leningrad State University (10 Petersburg Highway, Pushkin, St. Petersburg, Russia, 196605; academy.prof.com@gmail.com)

\section{INNOVATIONS IN THE PRODUCTION OF PUBLIC SERVICES: MAIN DIRECTIONS AND RELATED AREAS (literature review)}

\footnotetext{
Abstract. The paper is devoted to the study of innovations in the field of public services. It provides a literature review on innovation in the public sector, identifies issues, areas of contemporary research and related areas. The author makes a conclusion about the growing interest in innovations as a means of increasing the efficiency and quality of public services. The paper shows the change in approaches to innovation in the public sector that has intensified the development of relevant areas of practice, as well as scientific interest in such related topics as stakeholder engagement, leadership, network governance, the role of citizens in the innovation process, the value dimension of innovation, etc. When stating the undoubted development of management in the direction of innovativeness in its broadest sense, the author concludes that the sphere of public administration is the most inertial in relation to innovative development.

Keywords: innovation, social innovation, public service, public administration, co-production of public services, crowdsourcing, values, leadership, political networks
} 